\title{
INNOVATIVE RURAL DEVELOPMENT THROUGH NETWORKS AND PARTNERSHIPS ${ }^{1}$
}

\author{
J. Doitchinova, D. Zaimov* \\ Faculty of Economics, Trakia University, Stara Zagora, Bulgaria
}

\begin{abstract}
Development level of the rural areas in the different countries is usually associated with different forms of interaction and interdependence among producers, cooperative organizations, business and even research institutions. These forms and their various legal framework, as well as various levels of development trends and success have certain effect not only over the incomes generated, but also on the overall progress of the region they are located, including local community, agribusiness and its contribution over the local economy.

This paper aims to conceptualize an effective local development model, enabling a more effective organization and interaction of community resources and government support. Against this background a number of representative initiatives of innovation and innovative solutions that have emerged at the regional level will be analyzed.

The study corroborates that the determinants of the innovation process in the rural areas are not simply the policy measures undertaken, but rather the sense of responsibility and collaborative action taken on by the different stakeholders. This translates into the development of networks, involving local municipalities, for-profit organizations, as well as non-for profit organizations and cooperatives that explicitly pursue community well—being and regional identification.
\end{abstract}

Key words: rural areas in Bulgaria, innovative networks, cooperatives, producer organizations, local action group

\section{INTRODUCTION}

The level of development of the agricultural sector and rural areas in the different countries is usually associated with different forms of interaction and interdependence among producers, processing companies, business and even research organizations. These forms and their various legal framework, as well as various levels of development trends and success have certain effect not only over the incomes generated, but also on the overall progress of the region they are located, including local community, agribusiness and its contribution over the local economy. Defining the impact of the general agricultural policy reveals as highly problematic and controversial not only considering the expected results. The main argument supporting this statement is that generalization of the agricultural policy is less suitable and appropriate in the less developed regions,

\footnotetext{
* Correspondence to: Darina Zaimova, Industrial business and entrepreneurship, Faculty of Economics, Trakia University, Stara Zagora, Bulgaria,dzaimova@gmail.com
}

especially in the new Members States where the past policy experience still continues to impede their development progress. More over conducted policy hardly suited and is less efficient in supporting structurally weak rural areas. For that reason agricultural policy could not be assumed as a universal approach but rather as a common framework of legislative bundle. An ultimate objective of the recent policy efforts is to guarantee and promote sustainability of rural areas in social, economic and environmental aspect. Additionally there has been added the political and entrepreneurial issue that is to be improved in

\footnotetext{
${ }^{1}$ The research leading to these results has received funding from the People Programme (Marie Curie Actions) of the European Union's Seventh Framework Programme FP7/2007-2013/ under REA Grant Agreement No. 611490 (PIAPP-GA2013-611490).

${ }^{2}$ Leader Axis that is the fourth axis in the European Agricultural Fund for Rural Development contributes not only to the overall priorities of the other three axes, but also "(...) plays an important role for improving governance and mobilizing the endogenous development potential of rural areas."
} 
relation to provided institutional conditions and implementation requirements. The problems in achieving these generalized objectives are the differences ensuing from the regions" "endogenous development potential". This potential refers to their endowment first with 1) natural and man-made resources, and second with the 2) social services received from utilization of these resources, both on regional and national level.

Recently political and economic forums are underlining that the long-term perspectives of the agriculture will not improve, unless producers deal with the decreasing trend of the value added within the supply chain. The focus of this conclusion is primarily aimed at creating more incentives and visible results stemming from the effect of the different organizational forms and cooperative action. In that relevance emergence of the "new rural paradigm" is considered to be well-grounded. It "(...) is based on the notion of the multifunctionality of rural areas, where various sectors beyond agriculture are acknowledged to play a key role with regard to rural areas' competitiveness, and where investments across sectors are considered to be a more appropriate tool than farm subsidies alone. This shift can also be viewed as a change from an exogenous model of Rural Development, emphasising policy interventions "from outside", to a more endogenous approach based on the notion of Rural Development as a process involving multiple levels, dimensions and actors, that is also self-driven" (1).

The present scientific work is aimed at presenting and analyzing the different types of network structures and partnerships in the rural areas in Bulgaria and to estimate their capability for innovative regional development. The future innovative development of the rural areas is dependent on the activities and forms of collaboration and cooperative thinking of the local community while introducing new economic, social and ecological practices and preserving local identity as well.

\section{Innovation in rural areas}

Innovation fundamentally is a social process, following the ongoing debate on the traditional innovation concept that focuses on the material and technological innovations, while omitting the important social effects and sustainability issues. Binding the concepts of "innovation" and "enterprise" with the definition of being "social" is perceived both as a challenge and contradiction. Interpretations in this aspect proved to be fruitful and intriguing field of research interests and studies. The idea for innovation and its broader impact no longer represents only theoretical formulation, but turns out to be a practical phenomenon which gave impetus to unique bottom-up initiatives. Consequently, pursuing social goals through innovative approaches reveals as an underestimated opportunity from all of the concerned parties. This issue emerges with significantly different boundaries when it is referred to the communities in rural areas and the way their specific needs are determined and met. Performed reforms in the social and educational spheres, sporadic transfer of new technological decisions and disproportional labor market, and above all insufficient distribution of the European funds earmarked for modernization, have outlined a complicated and blurred process of introducing the innovation as sufficient mechanism and tool for promoting social inclusion and community well-being.

Thus the traditional understanding of innovation as a science-based technical process is not necessarily applicable to the rural situation, especially considering the growing diversity of European rural areas, characterized by a considerable variety of demography, economic and social structures, and calls for a more spatial targeting in rural development interventions, as well as for a new approach that considers the changes in rural development over the years and their main drivers, e.g. globalization, climate changes, revalorization of rural resources. The concept of innovation does not possess defined boundaries anymore, since the initiatives undertaken aim at various community-based needs. Therefore as long as they differ in their character and source, the innovation is apprehended through its multiple forms and particular cases. One profound interpretation is given recently by Murray, Caulier-Grice and Mulgan (2) who define innovation as: “(...) new ideas (product, services and models) that simultaneously meet social needs and create new social relationships and collaborations. (...) they are innovations that are both good for society and enhance society's capacity to act". It is reasonable to point out the definition, by which Hall et al. (3) formulate the innovation concept as " (...) an essentially social process involving interactive learning by doing, a process that can lead to new possibilities and approaches". Rationality of the process is considerably supported by well-defined and elaborated government policy. The innovation process, considered as a process of creation and exchange of knowledge, is shaped by relevant institutional structures in which it is embedded (4). During its realization the 
DOITCHINOVA J., et al,

interplay among different actors often creates conflicting points and contrary interests regarding economic, social or even political matters.

Mahroum et al. (5) define rural innovation as "the introduction of something new (a novel change) to economic or social life in rural areas, which adds new economic or social value to rural life". These authors also note the blurring in the divisions between rural and urban and also between the rural and urban innovation systems. Still, they argue that it is possible to distinguish three types of rural innovations:

$\checkmark$ innovations from rural areas aimed at applications elsewhere (such as organic food);

$\checkmark$ innovations for rural areas that have originated elsewhere (such as GIS) and

$\checkmark$ Innovations that is universal in nature but which have had strong impacts on rural life (such as the internet).

These three types of innovation do not occur in isolation from one another but are connected through market forces and the wider innovation system.

Significant role of the collaboration among the interested parties, such as formal institutions, local partnerships, coalitions or informal organizations is recognized through the definition of the "innovation system", which represents "(...) a group of organizations and individuals involved in the generation, diffusion, adaptation, and use of knowledge of socio-economic significance, and the institutional context that governs the way these interactions and process take place" (6). It represents the broader meaning of innovation as an interactive process, which involves interests with different character and purposes. The concept receives more elaborated description by allowing the term "innovation system" to focus on different spheres of social life, by clarifying its geographical and sector dimensions as well as the set of performed activities. Innovation system's concept provides for sophisticated framework encompassing:

$\checkmark$ partnership's patterns;

$\checkmark$ institutions as main sources for governance of these relationships and processes;

$\checkmark$ social element in innovation undertakings;

$\checkmark$ capacity development of the innovation systems.

Further interpretation introduces innovation beyond its particular meaning, as a process of crucial interaction between particular sector and science or as an expansion of sciencebased sectors. Besides this, innovation process provides for significant results with positive societal consequences and enhancing sustainable sector growth by "increasing their productivity, maximizing social inclusion and minimizing environmental damage" (7).

Taken together, innovation and rural development processes are complex by nature: they result from the interaction of many diversified and complementary actions, coordinated by different actors. Any innovation which lasts over a period of time supposes the implementation of previous actions which create the conditions for its implementation and viability. From this point of view, actions aiming to gain the support of the local population or create infrastructures which generate new dynamics become essential levers for consolidating innovations in the area (8). The innovative "coordinating" actions aim to create links between the communities and the economic actors. Two types of innovative coordinating actions can be identified: "broad" coordinating actions (such as community participation in carrying out area analyses, help give the area an identity and, for those who live there, the feeling of belonging to a community which collectively has a future) and more targeted coordinating actions, centred on a challenge to be met to develop the area. The innovative "structuring" actions aim to alter, on the basis of a selective action that is limited in time, the material or immaterial environment of the area to make it more favourable to the creation of activities. More generally speaking, all the innovations which relate to the protection of "amenities" (countryside, clean air, water, fauna, natural flora, etc.) fall into this category. The innovative "consolidating" actions aim to consolidate an economic activity in fields as diverse as agri-food, crafts, tourism, services for the population, cultural services, natural resource management services, etc. Actions of this type are in some way the concrete expression of the opportunities created by the two other types of innovative action. Their implementation is, for example, facilitated by the coordinating actions.

These three types of innovative action are therefore interlinked and complement one another in the development processes of rural areas. Each type prepares the other two and makes them possible, and as the actions progress, the area evolves and reaches more advanced stages of development. The evolution of rural areas can therefore be 
DOITCHINOVA J., et al,

compared to a spiral. Each stage (corresponding to each helix of the spiral represented on the graph) can be achieved through the combination of innovative coordinating, structuring and consolidating actions.

There is now widespread evidence that certain regions are systematically more disposed towards innovation than others, and the reasons for this relate variously to questions of the local industrial structure (9), the role of agglomeration externalities $(10 ; 11)$, the environment for entrepreneurship (12), the innovation and research favourable environment (13) and changing knowledge transactions costs (14).

Various recent and current trends have favoured innovation in rural areas including:

$\checkmark$ The diversification of local economies, which has allowed rural areas to become prime locations for new business ventures, in particular knowledge based businesses based upon 'clean' technology such as ICT.

$\checkmark$ Footloose entrepreneurs are also attracted to rural areas by perceived higher environmental quality and living standards.

$\checkmark$ Improved infrastructure and accessibility have encouraged businesses to locate in rural areas allowing the transfer of knowledge and the promotion of innovation.

$\checkmark$ Technological advancements and market trends too have encouraged small businesses to locate in rural areas, although typically accessibility to high speed broadband is far more restricted in availability in more remote rural regions.

$\checkmark$ New interactions between the local and the global have allowed once isolated communities to develop networks at an international scale.

Internal synergies increase innovative development, as new relationships between local areas expand allowing the absorption of new technologies and the emergence of potential new markets. The diffusing and transfer of innovation between rural areas are key areas for future discussion and there is a need for further analysis of how the needs of innovation are formulated and who formulates them (15).

Moreover, there is an increasing relationship between natural resources and innovation enhanced by the growing strategic importance of sustainable technologies that rely on rural resources such as crop-based energy, wind and wave power. These technologies bring new resources to rural areas and also create a renewed political interest in their role in the wider economy (16). Other trends are important in generating innovation in rural areas too including:

The continuing need to see technological advancements in food production (genetic modification, disease prevention and management, improved yields, crop/livestock production systems, supply chains and food security, soil/water management etc.), often centred on agricultural and land management colleges and instates.

Thus traditional activities that have historically been important in rural areas are acquiring new roles through increased diversification and broader multifunctional economic use.

The public sector is a critical employer in most rural economies and it is another important source of innovation. In-migrants into many rural areas are creating new demands for public services, including education, health and business support services.

In-migrants also expect a good quality infrastructure, including housing and transport. Thus this group creates both pressure and incentives for increased innovation in public services (17). More generally, innovation in public service provision and delivery is driven by the challenges of providing populations remote from major population centres and urban providers, such as high inefficient transport connectivity and access costs, and recruiting skilled workers. The more rapid ageing of the rural population places these areas at the vanguard of this demographic trend and thus opens the door for the further adoption of innovative methods of service delivery in future. Much has been written about innovation within the LEADER programme, which has been seen as a laboratory for the identification of the unique resources of rural areas and as a means of strengthening and consolidating social relations as tools for learning and innovation. The programme has allowed the testing of new rural development points and the applying of new policies at different stages within the intervention.

\section{Innovation networks of collaboration and partnerships?}

Lundvall et al. (18) identify that the interaction and interdependence in the innovation process presupposes non-linearity and complex relations among its participants. For that reason one unifying factor is stability of the 
DOITCHINOVA J., et al,

institutional environment that provides for accurate legal provisions and support in channeling market information, property right protection and regulation of competition. The World Bank report confirms that Institutions change slowly but constantly, either in response to shift in outside circumstances or as a result of group conflict and bargaining. Governance institutions are also of primary importance in determining how society addresses human development. Solution to overcome various potential problems is revealed in the opportunity to involve players, who represent both society and institutions through more accessible and efficient regulative structure. Scott (19) suggests that: "(...) regulative processes involve the capacity to establish rules, inspect or review others' conformity to them, and as necessary, manipulate sanctions - rewards or punishments - in attempt to influence future behavior".

There is a long history when talking about the different forms of collaboration and cooperation. In the different phases of their development these have played significant roles and have managed to deal with ones of the most important problems of the local communities and producers. Partially these problems are related to the way of using and distributing natural resources, others were created to protect form monopoly structures, third - with creating and sustaining typical products, services and brands to contribute to preserving local cultural and historical memory. Therefore the different forms of partnership have different functions, related to development and creation of the market and market rules, increase of the incomes and introducing the image and attractiveness of the rural area. The high concentration of small and medium sized agricultural enterprises has initiated building a competitive agro-industrial network on the base of specific product or geographical region and creating certain advantages through specialization and cooperation. Due to the diversity in terms of the counties' development potential, the undertaken public measures and private initiatives at European have registered varying impact at national level.

Additionally the main trends in structural development of agricultural sector have been characterised by the emergence of horizontal and vertical integration. In relevance to its integration level, organization could decide whether to transfer its profit from one sector of its production to other by changing the transfer price of resources. Consequently the main trends in structural development of agricultural sector have been characterised by the emergence of horizontal and vertical integration. The globalization process in the recent years puts forward the issue of transnational companies.

The process of horizontal integration relates to the increased market concentration and control; and in some cases to the establishment of dominating structures that tend to distort market functioning and competition. Vertical integration is perceived more likely as a way for the weaker party to gain competitive advantages along the value chain and strengthen its position by contractual arrangements. The globalization process in the recent years puts forward the issue of transnational companies. According to the statement of COPAC: "strengthening the economic power of farmers in a global food market increasingly concentrated in the hands of a few larger transnational companies" 3 . They have the opportunity to explore advantages of market niches, to optimize their production costs and to be more flexible and competitive.

In accordance of their way of establishment, the various network structures in the rural areas could be differentiated in traditional and new, mostly motivated by the community support and financed by external sources, such as national and European funds. Among traditional forms the most spread ones are these of the cooperatives and contract farming, which maintain the naturally emerged horizontal and vertical networks among producers, processors, wholesalers and others. Created networks and complicated linkages among various actors question their adaptability and opportunity to respond to the evolving community-based needs. In some particular cases the innovation comprises new approach towards specific problem. As formulated by Horton et al. (20): “(...) the traditional rules that once governed research and development organizations and their relations with stakeholders are becoming obsolete (...) In the era of increasingly rapid technological, economic, social and political change, people and organizations need to learn and adapt to changing conditions. Those that do not successfully innovate and develop new institutions and ways of working risk rapidly obsolescence."

${ }^{3}$ COPAC (1998), Committee for the promotion and advancement of cooperatives, Rome 
Cooperative and producer organization as the innovative "consolidating" actions and nets

Cooperative is one of the organizational forms, which has received through the years a significant spread and roles in countries with different development level of economy and agricultural sector. Its viability is supported by the immanent democracy rules and openmembership. These two general characteristics along with the voluntarily character of the membership represent the main sources of cooperative sustainability and adaptability. Cooperative adaptation towards environmental constraints, provided through: internal structural differentiation; strategic contracts and long-term arrangements for gaining market access; competitive possession of key production resources; and social oriented and environmental responsible policy, considerably changes the general perspective of cooperatives as organizations with limited strategies and capacity for their fulfillment. Furthermore Enke (1945) concluded that: "the cooperatives that advance the general economic welfare are those which seek to maximize net consumer's surplus (consumer's surplus plus profits)". Following this the most obvious characteristic of cooperatives is the change rate of their external environment which calls for active participation and efficient adjustment to the ongoing changes. The balance among members' interests, general cooperative well-being and interests of outside players complicates cooperative functions and activities, but also creates problems related to management and evasion of possible opportunistic behaviour.

Cooperative structures provide, assist and maintain a wide spectrum of economic, social, ethical demands and necessities, and for that reason their significance and role have received broad interest both from public and private authorities. This interest has also been supported by several theories in the economic and social field, which aim at explanation of cooperative structural characteristics and membership incentives. None of them has managed to capture thoroughly cooperatives' nature for the most obvious reason that during the years they have revealed as quite dynamic structures, which evolve progressively over time. These trends provide for larger perspective and opportunity to explore gradual changes and structural transformations in cooperative characteristics. Probably one of the most unique characteristics of cooperative development considers the balance achieved between the process of interaction and involvement in different economic, social and political scenarios, and preserving the initial cooperative principles and values at the same time.

Globalization has urged various authors (21) to consider cooperatives as an opportunity to limit re-allocalization of capital from rural areas, which usually happens with the other forms of organization. Even considering the inefficiency of such practices, especially in a long-term aspect, these at the same time contributes to the adaptation of the cooperative structures towards the changes business environment. Basically this results from the cooperative capacity to preserve local knowledge towards production, in comparison with the other hierarchical forms of production and exchange of competences (22). The essential role carried out by these organizations in the economy sector is a reflection of their unique way of establishment and management as: "(...) a collective, democratic way, economically feasible and competitive business projects with a social purpose" (23). Decentralization of the control from national to local level is a pre-requisite for motivating participation of the members based on the democratic principles. This is an opportunity for the cooperative to apply flexible specialization and quality to quarantee health and safety of the foods.

From economic perspective existence of cooperative structures is explained by several reasons, such as: incentives for market risk correction; scale economies and optimization of production and marketing process; stable market positions and reduction of transaction costs; collective bargaining and competitive advantage. Therefore it could be inferred that cooperatives are aimed at increasing their members' profit. Sustainability of the achieved results is maintained through quality policy and monitoring activity in order to minimize the fraction of the low quality producers and to promote incentives for high quality products. Collaborative and mutual interests appear to be efficient mechanism for diminishing production costs, increase of profit and risk minimization - “(..) cooperatives must, through their excellence, make money (...) without profit there is no way to serve member". Later on, to this statement has been added that: "(...) while fulfilling its purpose a cooperative must be at least as efficient and have at least as good a return on its invested capital as its competitors. A cooperative must be competitive..." (24).

Dynamics in rural development has prompt the emergence of new, personalized products and markets as well, which depend on new supply 
channels, new stakeholders, e.g. customer unions, etc. The good practices with innovative meaning for the regional development is suggested by an international research team IN-SIGHT, which identifies certain types of innovation, classified as economic, social, organizational and technical. Some of these such as sell of agricultural products over internet, collective shops and group purchases respond to the first three criteria for innovations, while the other - such as direct sells in the supermarket - as economic for the region.

In Bulgaria the main problem was the diversity of property relationships at the beginning of reforms. These shortcomings were defined by the perplexed combination of rights and duties and consequently different claims on economic benefits and cost responsibility. By this time all economic sectors have experienced a sharp decline not only because of the low level of domestic demand, but also because of the presence of significant export restrictions. This resulted in a transformation of the macroeconomic production structure, violated relations and a decrease of agricultural sector's share in the national economy. The main expectations were that agricultural share would continue declining until it reached the relevant levels in developed countries. According to case studies from that period, the degree to which the agricultural output in transition countries has declined is considered a confirmation factor for reform and that "(...) the absence of decline in output in a country more likely reflects failure to reform, rather than reform success"(25). Decline in the agricultural production came as a logical consequence from the elimination of budget subsidies, drop in consumer income and increase in input prices. But the general economic picture got even worse in the presence of an underdeveloped market infrastructure inherited from the pre-reform period.

The effect searched through reforms was not only an increase of total output, but achievement of stable productivity growth and cost optimization at microeconomic level. These reforms considered significant changes at production-level structures performed simultaneously and supported by the development of commercial and public institutions. New responsibilities and activities were imposed to producers, related mainly to the optimization of input utilization and consequently improvement of their efficiency. None of these sectored attempts were possible in the absence of market-based institutions and policy. The assessment of Bulgarian development during this transition period revealed significant problems regarding: vague structural strategy, production decline, financial instability of enterprises, limited investment opportunities, decline in customers' income and diminished monetary reserve as well.

European accession in 2007 and the implementation of the Common Agricultural Policy hold out remarkable opportunities for development of agricultural sector in Bulgaria. At the same time policy was bound to several requirements and conditions stipulated by its legal framework. Cooperative legal form in Bulgaria has always been a subject of special considerations and efforts towards its promotion as a reliable organizational form in the economic sector. Being part of the European Union provides sufficient incentives for Bulgaria to restore its cooperative movement basing on the positive examples in the other member states.

Nowadays in Bulgaria are registered and function close to 2000 cooperatives with 0,5 million members and 50000 employees. In these organizations are working almost 50 percent of the people with disabilities in Bulgaria. Cooperatives, regional cooperative unions and cooperative companies are organized in four national cooperative unions Central Cooperative Union, National union of agricultural cooperatives, National union of worker cooperatives and National union of cooperatives for people with disabilities.

While statistics indicate for job looses and instability at national level, most of the cooperatives show stable employment rate and viability. Increase has been reported in sartorial sector $(11 \%)$, in non-food industry (53\%). Investment activity also registers increase of $31 \%$ for 2012 . One of the strongest and most influential cooperative organizations in Bulgaria is the Central Cooperative Union (CCU). The Union represents 33 cooperative unions, which bring together 795 cooperatives with 149761 members; and nearly 12000 employees. All this shows that the union has sustainable market positions and social responsibility.

\section{Producer organization between cooperative and company}

The main effort and initiatives were towards the opportunity to create efficient organization of supply process, improvement of competitiveness of sector and market participants, enhancing producers' position and guarantee products' quality. A common 
problem for producers is the difficulty of gaining market access and still performing competitively in terms of quality, services and prices. In 2006, the EU-25 had 266 producers groups, 1594 producer organizations and 20 associations of producer organizations. By this time the level of organization is relatively low - 34 per cent and shows slight decrease with the accession of the 10 new member states in 2004. Until 2008 statistical data indicated for a slight positive effect of conducted policy. The economic crisis' consequences have initiated new measures for settling down and joining producer organizations, as they were given a wider range of tools of the already introduced crisis management: green harvesting/ nonharvesting, promotion and communication tools in times of crisis, training, harvest insurance, help in securing bank loans and financing of the administrative costs of setting up mutual funds. The observations so far have also envisaged that reforms have benefited the large-scale industry that has received considerable percentage of the EU funds. At the same time administration costs were pushed up because of the minute payments to small - scale farmers. Nevertheless, the efforts of the policy-makers to achieve positive effect in particular areas should not be omitted. Member States have different level of organization, therefore the recognition criteria for producer organizations was lowered in order to facilitate their establishment. This alleviating condition was beneficial for already existing organizations in the Old Member States and enhanced setting up new small-scale organizations. For the New Members States minimum recognition criteria contributed to concentration of market supply, but not in the same rate affected competitiveness and balance between market supply and demand. More or less these results were predictable in relation to the competitive advantage that more intensively organized regions possessed over regions where organizational rate was lower. Payment reliability, guaranteed purchase of production, as long as producer price level and technical assistance services were incentives to join producer organization only if they were supported by real examples for their achievement. This obviously was rather difficult in regions with low organizational rate.

Recent economic changes have revealed that market and price risk are in general problematic with respect to traditional insurance and contractual agreements. The characteristics of market crisis led to negative economic impact and market unbalances: low economic prises, excessive internal production, low domestic/ international demand, and increase of quantity of competitive imports. Producer organizations and their associations are major sources to guarantee competitiveness and viability of the sector. Membership in producer organization could be represented as a competitive factor and a sufficient way to improve the supply chain relations - the organizational capacity depends on their ability to adjust to the market criteria (logistics, quality management, financial capacity, price and cost competitiveness) (26).

Still there is the potential to develop new mechanisms intended to allow the transfer of risk outside the value chain. This transfer especially refers to individual producers from regions with not sufficient organizational level. The particular interest has shifted towards alternative contractual arrangements that transfer market risk from one agent to other.

The importance of the level of horizontal and vertical integration has been recognized again in respect of provided stimuli for establishment of producer groups. "Producer organisations are the basic actors in the fruit and vegetables regime, the decentralised operation of which they ensure at their level. In the face of ever greater concentration of demand, the grouping of supply through these organisations continues to be an economic necessity in order to strengthen the position of producers in the market. Such grouping should be effected on a voluntary basis and prove its utility by the scope and efficiency of the services offered by producer organisations to their members. Since producer organisations act exclusively in the interests of their members, they should be deemed as acting in the name and on behalf of their members in economic matters" (27). However it has also been recognized the unequal development of these structures considering the different organizational rate in the Members-States. Besides lowered recognition criteria (quantity, production value) the law envisages the opportunity for extension of services provided from the organizations to non-member producers. These services include production and marketing, as well environment protection undertakings.

In 2000 the already discussed agricultural policy and promoted measures for rural development has brought to positive change in the organizational rate in the sector. Of course this effect could not be estimated equivalently for the different types of production considering that the highest percentage of established producer organizations is in tobacco sector. In 2004 the number of these organizations was 15 , mainly registered as 
cooperatives. The first steps in the other sectors were insecure and rather sporadic - in dairy sector are settled down five producer organizations and only one is involved in production of meat and meat products.

The organizational rate and characteristics of the fruit and vegetable sector have undergone slow increase with the adoption of the new Regulation 11 from 2007 laying down specific rules on establishment of producer organizations ${ }^{4}$. Six producer organizations have been registered since 2004 and among them only one has adopted cooperative organizational form, while the rest have chosen to register under the Commercial Law as limited liability companies. Every member of these organizations has contract - for delivery, commission or production contract. This contract specifies the quantity and the quality of production in accordance to the annual production and marketing plans. Producers are obliged to sale through organization no less than 75 per cent of their production. By the time fixed by the organization, producers are obliged to transport their production (by own or organizational transport means) to the receiving stations where is assessed the quality of their production. At this stage the property right is transferred from the producers to the organization and the risk from damaging or spoiling the production as well. Until its final sale, production is preserved in storage and refrigerating facilities of the organization. Producers receive contracted payment for their production up to 30 days after its transportation to the receiving points of the organization. From the receivable amount are subtracted no more than 8 per cent for sorting, assembling, calibration and storage and no more than 5 per cent to cover marketing costs of production.

\section{Cluster as the innovative "structuring" actions between regional problems and global market challenges}

Clusters are the networks supported by the regional policy in different sectors and regions. With these structures is sought creation of sustainable interrelation between similar, connected and dependent competitive

\footnotetext{
${ }^{4}$ Regulation 11 from 15.05.2007 for the terms and order in recognition of organizations of fruit and vegetables producers and their associations and for the terms and order in alteration of approved operational programs, SG 42/ 29.05.2007
}

companies within same geographical region, with active channels for business activity, common specialized infrastructure, labour and service markets, etc. Within the context of the general project product or service produces, the members in the cluster are business and non-government organizations, research and academic organizations, public administration and physical entities. The network is the place, where the members from one or different sectors work together and add value to the product marketed. The emergence of "cluster policy" at sub-national level in Italy is supported by strong regional governance and active society awareness. In the context of agricultural policy implementation, the term "cluster policy" refers to provision of institutional incentives for companies in the sector to act as a competitive industrial framework. In the presence of high concentration of small agricultural companies it is interesting how they appear to be competitive in terms of quality, production costs and price? The answer is in their ability to behave as part of a group, binding together on the base of produced product or geographical region and benefiting from their common competitive advantage in terms of specialization, cooperation and flexibility. Due to diversity of characteristics and dynamics' level of its rural regions, still the most important aspect for clustering is the better accumulation of resources - both institutional and financial, is the degree of technological innovation, capital investment opportunity, intensification of production process, level of competitiveness and environmental undertakings.

Horizontal networks refer to collaboration between competitors within one sector (28), while covering initiatives, such as strategic alliances and enterprises, which are established to share information, social resources and informal relationships (29).

Vertical networks are consistently chosen to pursue the collective entrepreneurial strategy rooted in joint vertical integration and organizational innovation, while forming an organizational chain of units, which participate in all streams of products, services, finance and information. By expanding vertically, producers are able to "profit" by utilizing their low cost commodities as inputs into their "value-added" cooperatives. Vertically integrated clustering offers a number of important benefits. Each cluster is focused on a key primary industry, with a number of related midstream and downstream processes located close by. Other suppliers and service companies serving each stage of the value chain will also be encouraged to establish operations in the cluster, as well as research organizations, government institutions, etc. 
Even more, internal and external resources are contributing to innovation and fostering innovative process and competitiveness (30). Networks in the form of vertical linkages where inter-firm relationships are forged along the lines of the production and marketing chain within a specific industry, to promote processing and manufacturing, to advance certain manufacturers into a market niche; to encourage and host foreign investment; to acquire technological knowledge and managerial know-how; to pull the economy to higher employment and growth rates (31). The benefits of clustering and vertical integration have been evidenced in the large productivity gains and the remarkable growth in the production of manufactured goods.

This way SMEs are more innovative, while the information is available to the stakeholders, cooperative thinking is operationalizing the better achievement of goals and future planning. By pooling risk and credit demand, there is the opportunity to channel credit from formal institutions to SMEs at reasonable cost, while mobilizing deposits from the informal sector at minimal unit cost. The opportunities for pooling create a more conducive environment for enterprise networking among SMEs.

\section{Local action group as the innovative "coordinating" action and net}

During the previous programme period (20072013) close to 5\% of the EAFRD was earmarked to the Leader axis, with the exception of the Member States that joined the EU in 2004 and 2007 - the relevant percentage is $2.5 \%$. For this period were established 2290 LAGs, 123000 beneficiaries received financial support, and in total 136 million people in rural areas benefited from the implementation of the Leader programme.

As voluntarily and open coalition of leaders from different groups and social sectors (territorial government, non-government organizations, business, government organizations, schools, etc.), these organizations prepare and release long-term activities aimed at local development and finding solutions towards economic, social and ecological problems within one region (32). Inclusion of local community plays the key role for stimulating and not simply administrating territory. Some authors (33) claim that the most important characteristics of the created partnerships are the long-term relationships, consensus, sustainable decsionmaking and visibility.

The LEADER programme issued a methodological guide to identify, monitor and evaluate innovative processes occurring in local areas and to encourage the transfer of experience and knowledge between LEADER groups in different countries. The guide identifies eight key points as being important signifiers to analyse local innovation: mobilisation of the local population/social cohesion; identity of the area; activities and jobs; image of the area; migration, social and vocational integration; management of space and natural resources; study on Employment, Growth and Innovation in Rural Areas (SEGIRA); the evolution of technologies and competitiveness and access to markets (LEADER European Observatory).

There is a challenge for policy makers in the EU and its Member States to acknowledge the growing prospects of a new rural economy fuelled by innovation and to recognise the potential for rural areas to act as cites for innovation (34).

A general assumption in the context of LEADER is that the networking and cooperation of stakeholders from different sectors play an important role in creating new ideas and advancing innovations (35). Thereby LEADER could be a source of funding for innovative projects. At the same time publicprivate partnerships in the rural areas could perform as facilitators and organizers of all of the abovementioned forms of collaboration, which had significant contribution in innovative, sustainable and inclusive growth of rural areas. The combination of the good practices and new opportunities in the Programme for development of the rural areas, the networks could transform into a source for institutional, economic, ecological and innovative solutions in the regional context.

Local government is an important factor for mobilizing the local society and for development of rural areas in Bulgaria. Close to 60 municipalities in rural areas take part in projects for integrated development, financed by the European Union and the bilateral national programs aimed at development the capacity for planning and applying the policies for local development. In the process of structuring the development plans for the planning period 2007 - 2013, local action groups are involved into various collaborations - non-government organizations, educational and cultural institutions. These LAGs cover $24.7 \%$ of the rural municipalities and have a population of 800,758 th.people (less than $25 \%$ of the population in rural areas).

Implementing the Leader approach leads to: 
DOITCHINOVA J., et al,

$\checkmark$ strengthening of local civil society, build lasting relationships and their institutionalization in local action groups;

$\checkmark$ evaluating the potential of rural areas and the development of local development strategies for most rural areas of the country;

$\checkmark$ support for local businesses;

$\checkmark$ stimulate the diversification of the rural economy;

$\checkmark$ realization of various cultural initiatives for historic preservation;

$\checkmark$ improvement of the social services for the population.

All this led to the creation of networks between local authorities, business and NGO sector and to successful new forms of interaction and cooperation.

\section{CONCLUSIONS}

Diversity of the actors and the networks in rural areas is critical for their successful development. Within the Common Agricultural Policy (CAP) in Europe farmer organizations, producer groups have become useful mechanisms for the successful implementation of the policy schemes. Local action groups (LAGs) are also efficiently implementing their fundamental role for rural development and change. Different types of organizations have been developed to engage local rural communities in the process of community development.

In order to develop the different networks and their financing need to be implemented in the new programming period on an integrated approach - community-led local development (CLLD). It should be permissible tool implemented in all operational programs by establishing appropriate mechanisms for this model. This will provide a further basis for the unification of efforts and targets to achieve a harmonious and balanced territorial development, complementarity of aid ESIS concentration and adequacy of resources, effectiveness and efficiency of resources.

In the Partnership Agreement between the Republic of Bulgaria and the European Commission provides that the implementation of the approach CLLD and provide for specific financial parameters for allocating resources that amount to $5 \%$ of the budgets of individual funding programs approaches. It is necessary to create conditions for the timely launch of measures works, imbalance in the utilization of funds under the CMP, and to ensure better territorial coverage approach in rural and fishing areas in Bulgaria. In this connection, it should create the conditions for development, upgrade and improve the administrative capacity to manage and implement the approach CLLD at central and local level.

Special attention should be given to LAG that are responsible for the development of quality local development strategies and their law enforcement; achieving the objectives and implementing the priorities set out therein, as well as ensuring the sustainability of the results of applying the approach in order to obtain added value for the development of the territories; reduction in staff turnover capacity in the LAG.

\section{REFERENCES}

1. RuDi Rural Development Impacts, www.rudi-europe.net

2. Murray, R., Caulier-Grice, J. and Mulgan G. (2010). The open book of social innovation, NESTA.

3. Hall, A., Yoganand, B., Sulaiman, V.R., Clark, N. (2004). Postharvest innovations in innovations: a synthesis of recent cases. In Innovations in innovations: reflections on partnership, institutions and learning, ed. A. Hall, B. Yoganand, V.R. Sulaiman, R.S. Raina, C.S. Prasad, G.C. Naik, and N. Clark, 29-50.

4. Oyelaran-Oyeyinka, B. Lal, K., 2005. Internet Diffusion in sub-Saharan Africa: A CrossCountry Analysis, Telecommunications Policy 29:7, 507-527.

5. Mahroum, S., Atterton, J., Ward, N., Willams, A., Richard Naylor, Rob Hindle, Frances Rowe (2007), Rural Innovation, NESTA.

6. Hall, A., Yoganand, B., Sulaiman, V.R., Clark, N. (2004). Postharvest innovations in innovations: a synthesis of recent cases. In Innovations in innovations: reflections on partnership, institutions and learning, ed. A. Hall, B. Yoganand, V.R. Sulaiman, R.S. Raina, C.S. Prasad, G.C. Naik, and N. Clark, 29-50.

7. Pant, L. P., Odame, H. H., Hall, A., Sulaiman, R. V. (2008). Learning Networks Matter: Challenges to Developing Learning-Based Competence in Mango Production and Post-Harvest in Andhra Pradesh, India, UNU-MERIT.

8. European observatory LEADER, Innovation and Rural Development, The Observatory Dossiers No. 2 - 1997.

9. Iammarino, S., McCann, P., 2006. "The structure and evolution of industrial clusters: Transactions, technology and knowledge spillovers," Research Policy, Elsevier, vol. 35(7), pages 1018-1036, September. 
10.Acs, Z. (2002), Innovation and the growth of cities. Cheltenham: Edgar Elgar.

11.Van Oort, F.G. (2004), Urban growth and innovation. Spatially bounded externalities in the Netherlands. Aldershot: Ashgate.

12.Sternberg, T. (2011) Regional drought has a global impact. Nature, 472: 169.

13.Cozza, C., Ortega-Argilés, R., Piva, M., and Baptista, R., (2012) "Productivity Gaps Among EU regions", in Audretsch, D.B., Lehmann, $\quad$ E.E., Link, A.N., andStarnecker, A., (eds.), Technology Transfer in a Global Economy, Springer.

14.McCann, P. (2008) Globalization and economic geography: the world is curved, not flat, Cambridge J Regions Econ Soc(2008) 1 (3): 351-370.

15.European observatory LEADER, Innovation and Rural Development, The Observatory Dossiers No. 2 - 1997.

16. Atterton, J. and Ward, N. (2007) Diversification and Innovation in Traditional Landbased Industries, in Mahroum, S. et al. Rural Innovation, NESTA: London.

17.Mahroum, S., Atterton, J., Ward, N., Willams, A., Richard Naylor, Rob Hindle, Frances Rowe (2007), Rural Innovation, NESTA

18.Lundvall, B. et al. Introduction. Handbook of Innovation Systems and Developing Countries. Ed. Lundvall, Joseph, Chaminade, Vang. Cheltenham. Northampton: Edward Elgar. 2009. 1-30.

19.Scott W. R. (2001) Institutions and Organizations, SAGE Publications.

20.Horton, D., A. Alexaki, S. Bennett-Lartey, K.N. Brice, D. Campilan, F. Carden, J. de Souza Silva, L.T. Duong, I. Khadar, A. Maestrey Boza, I. Kayes Muniruzzam, J. Perez, M. Somarriba Chang, R. Vernooy, and J. Watts (2003). Evaluating capacity development: experiences from research and development organizations around the world. The Netherlands: ISNAR/ CTA; Canada: IDRC.

21.Mooney, Patrick, H.(1988). My Own Boss? Class, Rationality and the Family Farm. Boulder: Westview Press.

22.Hassenein, N., (1999). Changing the Way America Farms: Knowledge and Community in the Sustainable Agriculture Movement. Lincoln: University of Nebraska Press.

23. A system for good governance in the EU (Contribution to the White paper on Governance) Euro-Mediterranean network of social economy, pp.4-5.

24.A system for good governance in the EU (Contribution to the White paper on
Governance) Euro-Mediterranean network of social economy, pp.4-5.

25.Innovations systems and processes in the field of agricultural marketing: A crossnational analysis between France, Switzerland, Italy and the Netherlands INSIGHT: Strengthening Innovation Processes for Growth and Development Sixth Framework Programme, Priority 8.1 Policy-oriented research.

26.Zaimova, D. (2011) "Cooperative models in the agricultural sector: Development perspectives and solutions across Europe (Italy and Bulgaria)", LAP Lambert Academic Publishing, Germany.

27.Zaimova D.(2010) "Agro policy and strategies in Bulgaria's cooperative movement", In "Multifunctional agriculture and rural development", Special issue 2, Serbia, pp.632-638.

28.Hendrikse , G. W. J. (2003). Governance of chains and networks: A research agenda. Journal on Chain and Network Science 3 (1): 1-6.

29. O'Donnell, A., GilmorE, A., Cummin, D., Carson, D. (2001). The network construct in entrepreneurship research: a review and critique. Management Decision 39 (9): 749760.

30.Gellynck, X., Vermeire, B., Viaene, J. (2006). Innovation in the Food Sector: Regional Networks and Internationalisation. Journal on Chain and Network Science 6 (1): 21-30.

31.Lazzarini, S., Chaddad, F., Cook, M. (2001). Integrating supply chain and network analyses: The study of netchains. Journal on Chain and Network Science 1 (1): 7-22.

32.Doitchinova, J., Miteva, A., Stoyanova Z. (2012). The Process of creating local action group in Bulgaria - problems and prospects, Scientific Annals of the "Alexandru Ioan Cuza" University of Iasi , Economic Sciences Section, Vol 59, No 2.

33.Furmankiewicz, M. (2008). Enhancing endogenous development in rural areas: the implementation of the LEADER pilot programme in Poland, Wrocław University of Environmental and Life Sciences.

34.Mahroum, S., Atterton, J., Ward, N., Willams, A., Richard Naylor, Rob Hindle, Frances Rowe (2007), Rural Innovation, NESTA.

35.Dargan, L., Shucksmith, M. (2008). LEADER and Innovation, Sociologia Rutalis, Vol.48, Number 3: 274-291. 